\title{
Editorial \\ Analysis of Crop Genetic and Germplasm Diversity
}

\author{
Antonio M. De Ron *(D) and Ana Paula Rodiño *(iD)
}

Misión Biológica de Galicia (MBG), Spanish National Research Council (CSIC), 36143 Pontevedra, Spain

* Correspondence: amderon@mbg.csic.es (A.M.D.R.); aprodino@mbg.csic.es (A.P.R.);

Tel.: +34-986-854-800 (A.M.D.R. \& A.P.R.)

check for updates

Citation: Ron, A.M.D.; Rodiño, A.P. Analysis of Crop Genetic and Germplasm Diversity. Agronomy 2022, 12, 91. https://doi.org/10.3390/ agronomy12010091

Received: 15 December 2021 Accepted: 27 December 2021 Published: 30 December 2021

Publisher's Note: MDPI stays neutral with regard to jurisdictional claims in published maps and institutional affiliations.

Copyright: (C) 2021 by the authors. Licensee MDPI, Basel, Switzerland. This article is an open access article distributed under the terms and conditions of the Creative Commons Attribution (CC BY) license (https:// creativecommons.org/licenses/by/ $4.0 /)$.
Plant genetic resources are the basis for the genetic improvement of cultivated plants and future food and feed security. The interactions of plants with their agrosystem, the influence of different cropping systems, and the resistance of crops to biotic and abiotic stresses, as well as the adaptation of plants to different environmental conditions under the current changing conditions, are relevant aspects.

Agricultural biodiversity is the diversity of crops and their wild relatives, trees, animals, microbes, and other species relevant to agricultural production. Food and feed biodiversity is crucial to fight malnutrition and diet-related diseases. A diverse diet increases the likelihood of consuming adequate amounts of the full range of nutrients essential to human health.

The genetic diversity of several crop species is presented in this publication. This biodiversity was assessed by morphological and agronomical traits and nutritional characters, also including molecular diversity and tolerance/resistance to abiotic and biotic stresses.

The analysis of biodiversity in crops is focused on different goals: use of germplasm for breeding; adaptation of germplasm to different environments; evolution of adapted varieties and the nutritional and quality properties. The agromorphological variation, genetic variability, and quality characters were studied in species of the Poaceae family as fonio ((Digitaria exilis (Kippist) Stapf)) [1], maize (Zea mays L.) [2], rice (Oryza sativa L. spp. Indica and O. sativa spp. Japonica) [3,4]), and Cynodon [5]. Some horticultural crops such as eggplant (Solanum melongena L.) [6,7] and Capsicum (several species) [8,9] were studied, presented in this volume, with regard to morphological, sensorial, and chemical characterization and adaptation to different conditions. With regard to legume crops, the diversity of pigeonpea (Cajanus cajan (L.) Millspaugh) was highlighted [10].

Fonio is an ancient orphan cereal, cultivated by resource-poor farmers in arid and semi-arid regions of West Africa, who conserved and used the cereal for nutrition and income generation. Furthermore, this study highlighted agromorphological descriptors that discriminate fonio accessions and provide useful information for parental selection with economically important agronomic traits [1]. Seven maize races of the central high plateau of Mexico were characterized using a combined analysis of 13 morphological traits and 31 microsatellite loci. Principal component analysis separated the different accessions into well-defined groups using the first three principal components. The accessions of the Arrocillo Amarillo and Elotes Cónicos races did not exhibit a grouping pattern, indicating greater genetic complexity [2]. Rice (Oryza sativa L.) contains many high-value nutritional compounds, including nutraceutical lipid compounds that offer health benefits. Cluster analysis sorted the germplasm into nine clusters, based on their nutraceutical lipid content. TU-010, TU-027, TU-093, and TU-244 genotypes had the highest levels, making them a potentially useful genetic resource in breeding programs for nutraceutically improved rice. The findings of this study can support the introduction of novel rice varieties with high added-value bioactive properties [3]. The japonica rice variety in northeastern China is well known because of its high quality. Eating and cooking qualities (ECQs) are the most important factors that determine cooked rice quality. The japonica varieties in northeastern China 
exhibited a narrow genetic basis. These results further elucidate the genetic basis of ECQs of japonica varieties in northeastern China and provide local breeders some assistance for improving ECQs of rice grain in rice breeding [4]. The Cynodon spp. collection maintained by the United States Department of Agriculture National Plant Germplasm System (USDA-NPGS) has limited information on nutritive value (NV) traits. Genetic variables revealed the presence of significant genetic variability, indicating potential improvements for NV through breeding. Specifically, P and IVDOM presented large variation, while NDF had lower diversity but some accessions exhibited lower NDF than Tifton 85. Low GHI, except for IVDOM, indicated genotypic stability and potential for selecting improved accessions under fewer harvests. Breeding line 240, PI-316510, and PI-3166536 presented superior NV than Tifton 85 [5]. The methodology and the approaches used may provide a model for the enhancement of other vegetable crop diversity toward adaptability to the cropping condition decision. This result revealed the importance of preserving eggplant germplasm for future varietal development and that open-field cropping condition is more suitable under Malaysia's agroecology [6]. Due to the particularity of environment and isolation from the mainland, Greek islands represent a natural laboratory for comparing the diversity of landraces from the islands with those of the Greek mainland. Based on the available data, the Greek eggplant landraces present considerable morphological and genetic diversity with some differentiation signatures between the island and the mainland accessions. These results have implications for the conservation of Greek landraces and suggest that Greece might be considered as part of a secondary center of diversity for eggplant in the Mediterranean basin [7]. Six distinct groups of these landraces and the joint analysis presented an entanglement rate of 0.58 , offering evidence for the divergence of accessions between the groups of both dendrograms. The Bayesian analysis allowed the distinction of two clusters for SSR. Significant variability was observed among accession with the potential to integrate several breeding programs [8]. The highest capsaicin concentration was recorded in accessions $16,209(55.90 \mathrm{mg} / \mathrm{g})$ and 10,757 (48.80 mg/g). The highest antioxidant value was recorded in accessions 17,750 (90.85 mg/g) and 15,661 (87.03 mg/g). All these characteristics are important for increasing industrial use and genetic improvement processes. These results show the existence of significant genetic variability within the genus Capsicum [9]. Knowledge of the genetic diversity in pigeonpea is essential for an effective breeding program. In one of the presented studies, the objective was to assess the genetic diversity among diverse pigeonpea accessions to select complementary and unique genotypes for breeding. The selected high-yielding and early maturing genotypes may be recommended as parental lines for breeding and grain yield improvement in Malawi or similar agro-ecologies [10].

Some of the research included in this volume focused on molecular variation. Cereal as maize [11,12] and wheat (Triticum aestivum L.) [13-16] was studied in different ways, including nucleotide diversity and genetic association analysis, population structure, allelic variation, congruity of the polymorphisms in the expressed and noncoding parts of genes, and management of high-throughput genotyping data. Medicinal crops as ginseng (Panax ginseng C.A. Meyer) [17,18], laurel (Laurus nobilis L.) [19], and tea (Camellia sinensis (L.) Kuntze) [20] are also included in this volume. Genetic variation and population structure and phytochemical and molecular diversity were studied in these crops. The variation in a relevant tuber crop, sweet potato (Ipomoea batatas L. Lam) [21,22], was assessed using chloroplast SSR markers and sequence diversity of biosynthesis pathways. In legumes, the genetic diversity in cowpea (Vigna unguiculata (L.) Walp.) [23] was studied to identify an important hotspot of variation.

Root length is a determining factor of the root system architecture, which is essential for the uptake of water, nutrients, and plant anchorage. The results of the study by [11] reveal that ZmMADS60 may be involved in the elongation of primary and lateral roots in the seedling stage and that significant variants can be used to develop functional markers to improve root length in maize [11]. Adequate knowledge and understanding of the genetic diversity and inter-trait relationships among elite maize inbred lines are crucial 
for determining breeding strategies and predicting hybrid performance. A wide range of genetic variability was observed among the inbred lines, indicating that they are an invaluable resource for breeding for combined heat and drought (HD) tolerance in maize breeding programs, especially in West and Central Africa [12]. Wheat landraces are currently being explored mainly as a source of allelic variation related to crop resilience and low-input adaptation. Characterization of their high- and low-molecular-weight glutenin subunits can aid breeders to select as donor local materials those ensuring good end-use properties in the derived elite cultivars. Some of the landraces, showing outstanding values for the gluten quality parameters analyzed, might be directly used by farmers interested in the cultivation of traditional varieties for specialized food markets [13]. The objective of another presented study was to analyze the mutation frequency in Pin genes and their influence on grain hardness in 118 modern bread-wheat cultivars and breeding lines and 80 landraces from Poland. Based on grain hardness measured by a single-kernel characterization system (SKCS), the analyzed cultivars and lines were categorized into different classes according to a previously proposed classification system [14]. The previously defined pairs of primers GliB1.1 and GliB1.2 were found to produce three and four principal variants, respectively, of PCR sequence length for the $\gamma$-gliadin pseudogene in 46 Triticum aestivum L. cultivars from 15 countries carrying 19 known alleles at the Gli-B1 locus. In addition to revealing its evolutionary significance, this information is of potential use in wheat breeding, and we believe that novel variants of the Gli-B1 locus will likely be found in hitherto unstudied germplasm [15]. In this study, a core collection of Spanish landraces of bread wheat was created using high-throughput genotyping technologies (DArTseq), which yielded more than $50 \mathrm{~K}$ molecular markers. This core collection, which includes a broad range of adapted genotypes, can be efficiently utilized for mining new alleles for useful traits in wheat breeding [16]. Ginseng (Panax ginseng C.A. Meyer) has long been used as a medicinal herb in Korea and China. Since ginseng originated from wild ginseng with low genetic diversity, it is also expected to have low genetic diversity. In another study, the genetic diversity of 451 ginseng accessions conserved in the National Agrobiodiversity Center (NAC) in South Korea was analyzed. The results of this study suggest that NAC should increase the genetic diversity of ginseng accessions for breeding programs, and alternatives are needed for securing ginseng genetic resources [17]. There have been limited research efforts to analyze the genetic diversity and population structure of ginseng germplasm conserved in the National Agrobiodiversity Center (NAC). The results of this study provide molecular evidence for the narrow genetic base of ginseng germplasm in NAC. For the broad understanding and efficient use of ginseng germplasm, it is necessary to analyze functional factors and to evaluate morphological traits [18]. Laurel is a medicinally important plant and is known to the world for its essential oil. Turkey is the main market in the laurel leaf trade, sharing about $90 \%$ of the world trade. Here, the authors aimed to elucidate the genetic diversity and population structure of 94 Turkish laurel genotypes collected from 26 provinces and four geographical regions using interprimer binding-site (iPBS) retrotransposon markers. The information provided in this work will be helpful for the scientific community to devote more attention to this forgotten but medicinally important plant [19]. For the direct use of tea germplasm in breeding programs, a target-oriented core collection (TOCC) that retains the genetic diversity and various phytochemicals in tea is needed. This is the first report describing the development of a TOCC retaining the diversity of phytochemicals in tea germplasm. This TOCC will facilitate the identification of the genetic determinants of trait variability and the effective utilization of phytochemical diversity in crop improvement programs [20]. Sweet potato is an important food crop, widely cultivated in the world. In one of the included studies, nine chloroplast simple sequence repeat (cPSSR) markers were used to analyze the genetic diversity and relationships of 558 sweet potato accessions in the germplasm collection of the National Agrobiodiversity Center (NAC). The results of this study confirm that the genetic diversity of the female parents of sweet potato accessions conserved at the NAC is low, and therefore, more sweet potato accessions need to be collected. These results 
will help to establish an efficient management plan for sweet potato genetic germplasms at the NAC [21]. Sweet potato is also an important starch-producing crop, but little is known about the genetic variations in starch biosynthesis and sucrose metabolism genes. In this research, sequence variations between germplasms were identified in 20 genes involved in starch biosynthesis and sucrose metabolism, demonstrating the diversity in intron-loss alleles among sweet potato germplasms. These findings provide critical genetic information and useful molecular markers for revealing the regulatory mechanism of starch properties [22]. Cowpea is a multiple-purpose, drought-tolerant leguminous pulse crop grown in several dry tropical areas. Its domestication center is believed to be East or West Africa, where a high level of genetic diversity is apparently still found. However, detailed genetic information is lacking in many African countries, limiting the success of breeding programs. The high genetic diversity found in Mozambique sustains the importance of local genetic resources and farm protection to enhance genetic diversity in modern varieties of cowpea worldwide [23].

The performance of crops under abiotic and biotic stresses was analyzed regarding pests, diseases, and abiotic factors. The cereals studied were triticale $(\times$ Triticosecale Wittmack) [24], wheat [25], rice [26,27], and barley (Hordeum vulgare L.) [28]. Resistance to diseases as rust and powdery mildew, together with blast resistance, phosphorous deficiency, and salt stress were evaluated in this group of crops. In legumes, studies on resistance to anthracnose in lentils (Lens spp.) [29], the inheritance and expressivity of neoplasm trait in crosses between the domestic pea (Pisum sativum subsp. sativum) and wild pea (Pisum sativum subsp. elatius) [30], and the implications of the symbiotic nitrogen fixation in common bean (Phaseolus vulgaris L.) [31] under water stress are presented. The isolate-dependent inheritance of resistance against Pseudoperonospora cubensis of a horticultural crop (Cucumber) [32] was also analyzed.

Hexaploid triticale is a cultivated hybrid that combines wheat and rye properties. It has a better ability to be grown on poor soils, compared to wheat. In a review study, the recent state of the art of pre-breeding studies is presented, which are focused on the transfer of leaf and stripe rust resistance genes from Aegilops species into cultivated triticale using the distant crossing and chromosome engineering approach [24]. Wheat-Psathyrostachys huashanica-derived lines were developed by crossing common wheat and P. huashanica Keng ( $2 \mathrm{n}=2 \mathrm{x}=14$, NsNs) using embryo culture; line H5-5-4-2 was selected with immunity to powdery mildew at both growth stages. The results indicate that resistant line H5-54-2 was a wheat-P. huashanica 1 Ns disomic addition line [25]. The objectives of another presented study were to evaluate the newly developed blast-resistant rice lines in varied environmental conditions, precisely measure the response of the advanced lines in multiple environments, and classify the genotypes into groups that could serve as varieties for commercial cultivation. A low genetic advance was observed in some agronomical traits. Cluster analysis classified the evaluated genotypes into six groups that were recommended as varieties for commercial cultivation in Malaysia and other rice-growing regions [26]. The yield of rice is severely limited by phosphorus deficiency. This study aimed to identify P-deficiency-responsive differentially expressed proteins in rice through analysis of leaf proteome of contrasting P-responsive rice cultivars under P-deficiency conditions because genetic variability has been found in rice cultivars for adaptive response to $\mathrm{P}$ deficiency, and a controlled regulatory system is involved in the $\mathrm{P}$ deficiency adaptation response. This study could help to unravel the complex regulatory process that is involved in adaptation to $\mathrm{P}$ deficiency in rice [27]. The interaction between salinity and nitrogen metabolism has been investigated in two barley landraces, one tolerant ("100/1B") and one susceptible to salinity ("Barley medenine") from the Middle East and North Africa region. Specific enzymatic activities and occurrence can be used to determine the stress responsiveness of different landraces. It is suggested that a rapid increase in the activities of G6PDH, APX, and nitrogen assimilation enzymes represents an index of tolerance in "100/1B" and a stress symptom in "Barley medenine" [28]. Anthracnose, caused by the fungal pathogen Colletotrichum lentis, is a severe disease in lentils, causing premature defoliation, necrotic 
stem lesions that lead to plant wilting, and death in susceptible varieties. Two races of C. lentis ( 0 and 1$)$ have been described so far. Most of the collection studied was highly susceptible, but some levels of resistance were identified in about $15 \%$ of the accessions. Selected accessions showed potential to integrate several breeding programs [29]. The Neoplasm trait in pea pods is reported to be due to the lack of ultraviolet (UV) light in glasshouse conditions or in response to pea weevil (Bruchus pisorum L.) damage. This pod deformation arises from the growth of non-meristematic tissue on pods of domesticated peas. There was no relationship between neoplasm and damage by pea weevil under heavy insect epidemics under field conditions. The neoplasm occurring under glasshouse conditions may be due to one or to a combination of environmental factors. Since wild peas are useful genetic resources for breeding programs aiming at fresh pea production that could be utilized under glasshouse conditions, negative selection could be considered in segregating populations [30]. The objective of this research was to study the performance of common bean genotypes under water-deficit stress, and how it affects their symbiotic relationship with different Rhizobium strains in both greenhouse and field conditions. The genotype-strain relationship was very specific, and the local strains achieved the greatest productivity with some genotypes in irrigated and drought conditions that enable their application as inoculating strains, particularly relevant for the environmental impact of agriculture [31]. Wild accessions of cucumber were evaluated for resistance against each of the 23 isolates of the downy mildew oomycete Pseudoperonospora cubensis. F2 progeny plants of the cross between two resistant accessions were resistant, except for a few plants that were partially susceptible, suggesting that some of the resistance genes in PI 197088 and PI 330328 are not allelic [32].

In conclusion, in agricultural production, agrobiodiversity supports long-term productivity, resilience, and multiple ecosystem services, boosting yields in quality and quantity, increasing soil and water quality, and reducing the need for synthetic fertilizers. It also makes farmer livelihoods more resilient, reducing yield losses due to climate change and pest damage. Broadening the types of cultivated plants also benefits the environment, increasing the abundance of ecological services, such as pollinators and beneficial soil organisms, and reducing the risk of pests and diseases. Agrobiodiversity, when adequately maintained, also could support options for unknown future needs; additionally, using biodiversity-based solutions on farms can also decrease emissions of greenhouse gases that contribute to climate change.

Author Contributions: A.M.D.R. and A.P.R. wrote the paper. All authors have read and agreed to the published version of the manuscript.

Funding: This research received no external funding.

Acknowledgments: The authors thank the support from the projects INIA-RFP2015-00008-C04-03 and CSIC-202040E190, and Diputación de Pontevedra (Spain) for their experimental work.

Conflicts of Interest: The authors declare no conflict of interest.

\section{References}

1. Ibrahim Bio Yerima, A.R.; Achigan Dako, E.G.; Aissata, M.; Sekloka, E.; Billot, C.; Adje, C.O.A.; Barnaud, A.; Bakasso, Y. Agromorphological Characterization Revealed Three Phenotypic Groups in a Region-Wide Germplasm of Fonio (Digitaria exilis (Kippist) Stapf) from West Africa. Agronomy 2020, 10, 1653. [CrossRef]

2. Rocandio Rodriguez, M.; Santacruz Varela, A.; Cordova Tellez, L.; Lopez Sanchez, H.; Hernandez Bautista, A.; Castillo Gonzalez, F.; Lobato Ortiz, R.; Garcia Zabala, J.J.; Lopez, P.A. Estimation of Genetic Diversity in Seven Races of Native Maize from the Highlands of Mexico. Agronomy 2020, 10, 309. [CrossRef]

3. Harakotr, B.; Prompoh, K.; Boonyuen, S.; Suriharn, B.; Letrrat, K. Variability in Nutraceutical Lipid Content of Selected Rice (Oryza sativa L. spp. indica) Germplasms. Agronomy 2019, 9, 823. [CrossRef]

4. Yang, Y.; Xu, X.; Zhang, M.; Xu, Q.; Feng, Y.; Yuan, X.; Yu, H.; Wang, Y.; Wei, X. Genetic Basis Dissection for Eating and Cooking Qualities of Japonica Rice in Northeast China. Agronomy 2020, 10, 423. [CrossRef]

5. de Souza, C.; Lopez, Y.; Munoz, P.; Anderson, W.; Dall'Agnol, M.; Wallau, M.; Rios, E. Natural Genetic Diversity of Nutritive Value Traits in the Genus Cynodon. Agronomy 2020, 10, 1729. [CrossRef] 
6. Mat Sulaiman, N.N.; Rafil, M.Y.; Duanglit, J.; Ramiee, S.I.; Phumichal, S.; Oladosu, Y.; Datta, D.R.; Musa, I. Genetic Variability of Eggplant Germplasm Evaluated under Open Field and Glasshouse Cropping Conditions. Agronomy 2020, 10, 436. [CrossRef]

7. Gramazio, P.; Chatziefstratiou, E.; Petropoulos, C.; Chioti, V.; Mylona, P.; Kapotis, G.; Vilanova, S.; Prohens, J.; Papasotiropoulos, V. Multi-Level Characterization of Eggplant Accessions from Greek Islands and the Mainland Contributes to the Enhancement and Conservation of this Germplasm and Reveals a Large Diversity and Signatures of Differentiation between both Origins. Agronomy 2019, 9, 887. [CrossRef]

8. Alvares Bianchi, P.; Almeida da Silva, L.G.; Da Silva Alencar, A.A.; Araujo Diniz Santos, P.H.; Pimenta, S.; Pombo Sudré, C.; Dalia Corte, L.E.; Azeredo Gonçalves, L.S.; Rodrigues, R. Biomorphological Characterization of Brazilian Capsicum Chinense Jacq. Germplasm. Agronomy 2020, 10, 447. [CrossRef]

9. Paredes Andrade, N.J.; Monteros Altamirano, A.; Tapia Bastidas, C.G.; Serensen, M. Morphological, Sensorial and Chemical Characterization of Chilli Peppers (Capsicum spp.) from the CATIE Genebank. Agronomy 2020, 10, 1732. [CrossRef]

10. Yohane, E.N.; Shimells, H.; Laing, M.; Mathew, I.; Shayanowako, A. Phenotypic Divergence Analysis in Pigeonpea [Cajanus cajan (L.) Millspaugh] Germplasm Accessions. Agronomy 2020, 10, 1682. [CrossRef]

11. Li, P.; Ge, Z.; Wang, H.; Wel, J.; Wang, Y.; Xu, Y.; Yang, Z.; Xu, C. Nucleotide Diversity and Association Analysis of ZmMADS60 with Root Length in the Maize Seedling Stage. Agronomy 2020, 10, 342. [CrossRef]

12. Osuman, A.S.; Badu-Apraku, B.; Ifie, B.E.; Tongoona, P.; Obeng-Blo, E.; Garcia Oliveira, A.L. Genetic Diversity, Population Structure and Inter-Trait Relationships of Combined Heat and Drought Tolerant Early-Maturing Maize Inbred Lines from West and Central Africa. Agronomy 2020, 10, 1324. [CrossRef]

13. Chacon, E.A.; Vazquez, F.J.; Giraldo, P.; Carrillo, J.M.; Benavente, E.; Rodriguez Quijano, M. Allelic Variation for Prolamins in Spanish Durum Wheat Landraces and Its Relationship with Quality Traits. Agronomy 2020, 10, 136. [CrossRef]

14. Przyborowsky, M.; Gasparis, S.; Kala, M.; Orczyk, W.; Orczyk, A.N. The Variability of Puroindoline-Encoding Alleles and Their Influence on Grain Hardness in Modern Wheat Cultivars Cultivated in Poland, Breeding Lines and Polish Old Landraces (Triticum aestivum L.). Agronomy 2020, 10, 1075. [CrossRef]

15. Popovych, Y.; Chebotar, S.; Meinik, V.; Rodriguez Quijano, M.; Pascual, L.; Rogers, W.J.; Metakovsky, E. Congruity of the Polymorphisms in the Expressed and Noncoding Parts of the Gli-B1 Locus in Common Wheat. Agronomy 2020, 10, 1510. [CrossRef]

16. Pascual, L.; Fernandez, M.; Aparicio, N.; Lopez Fernandez, M.; Fité, R.; Giraldo, P.; Ruiz, M. Development of a Multipurpose Core Collection of Bread Wheat Based on High-Throughput Genotyping Data. Agronomy 2020, 10, 534. [CrossRef]

17. Lee, K.J.; Sebastin, R.; Kim, S.H.; Yoo, E.; Lee, S.; Cho, G.T.; Kang, M.; Hyun, D.Y. Genetic Composition of Korean Ginseng Germplasm by Collection Area and Resource Type. Agronomy 2020, 10, 1643. [CrossRef]

18. Lee, K.J.; Lee, J.R.; Sebastin, R.; Cho, G.T.; Hyun, D.Y. Molecular Genetic Diversity and Population Structure of Ginseng Germplasm in RDA-Genebank: Implications for Breeding and Conservation. Agronomy 2020, 10, 68. [CrossRef]

19. Karik, U.; Nadeem, M.A.; Habyarimana, E.; Ercisli, S.; Yildiz, M.; Yilmaz, A.; Yang, S.H.; Chung, G.; Baloch, F.S. Exploring the Genetic Diversity and Population Structure of Turkish Laurel Germplasm by the iPBS-Retrotransposon Marker System. Agronomy 2019, 9, 647. [CrossRef]

20. Hyun, D.Y.; Gi, G.Y.; Sebastin, R.; Cho, G.T.; Kim, S.H.; Yoo, E.; Lee, S.; Son, D.M.; Lee, K.J. Utilization of Phytochemical and Molecular Diversity to Develop a Target-Oriented Core Collection in Tea Germplasm. Agronomy 2020, 10, 1667. [CrossRef]

21. Lee, K.J.; Lee, G.A.; Lee, J.R.; Sebastin, R.; Shin, M.J.; Cho, G.T.; Hyun, D.Y. Genetic Diversity of Sweet Potato (Ipomoea batatas L. Lam) Germplasms Collected Worldwide Using Chloroplast SSR Markers. Agronomy 2019, 9, 752. [CrossRef]

22. Zhang, K.; Luo, K.; Li, S.; Peng, D.; Tang, D.; Lu, H.; Zhao, Y.; Lv, C.; Wang, J. Genetic Variation and Sequence Diversity of Starch Biosynthesis and Sucrose Metabolism Genes in Sweet Potato. Agronomy 2020, 10, 627. [CrossRef]

23. Figueira Gomes, A.M.; Draper, D.; Talhinhas, P.; Batista Santos, P.; Simoes, F.; Nhantumbo, N.; Massinga, F.; Ramalho, J.C.; Marques, I.; Ribeiro-Barros, A.I. Genetic Diversity among Cowpea (Vigna unguiculata (L.) Walp.) Landraces Suggests Central Mozambique as an Important Hotspot of Variation. Agronomy 2020, 10, 1893. [CrossRef]

24. Ulaszewski, W.; Kwlatek, M.T. Aegilops Species for the Improvement of the Leaf and Stripe Rust Resistance in Cultivated Triticale ( $\times$ Triticosecale Wittmack). Agronomy 2020, 10, 1991. [CrossRef]

25. Han, J.; Liu, Y.; Hou, C.; Li, J.; Wang, J.; Zhang, Q.; Yang, Q.; Chen, X.; Wu, J. A 1Ns Disomic Addition from Psathyrostachys Huashanica Keng Confers Resistance to Powdery Mildew in Wheat. Agronomy 2020, 10, 312. [CrossRef]

26. Sabri, R.S.; Rafii, M.Y.; Ismall, M.R.; Yusuff, O.; Chukwu, S.C.; Hasan, N. Assessment of Agro-Morphologic Performance, Genetic Parameters and Clustering Pattern of Newly Developed Blast Resistant Rice Lines Tested in Four Environments. Agronomy 2020, 10, 1098. [CrossRef]

27. Tantray, A.Y.; All, H.M.; Ahmad, A. Analysis of Proteomic Profile of Contrasting Phosphorus Responsive Rice Cultivars Grown under Phosphorus Deficiency. Agronomy 2020, 10, 1028. [CrossRef]

28. Azalez, F.E.B.; Ayadi, S.; Capasso, G.; Landi, S.; Paradisone, V.; Jallouli, S.; Hammami, Z.; Chamekh, Z.; Zouari, I.; Trifa, Y.; et al. Salt Stress Induces Differentiated Nitrogen Uptake and Antioxidant Responses in Two Contrasting Barley Landraces from MENA Region. Agronomy 2020, 10, 1426.

29. Barilli, E.; Moral, J.; Aznar Fernandez, T.; Rubiales, D. Resistance to Anthracnose (Colletotrichum lentis, Race 0) in Lens spp. Germplasm. Agronomy 2020, 10, 1799. [CrossRef] 
30. Sari, H.; Sari, D.; Eker, T.; Aydinoglu, B.; Canci, H.; Ikten, C.; Gokturk, R.S.; Zeybek, A.; Bakir, M.; Smykal, P.; et al. Inheritance and Expressivity of Neoplasm Trait in Crosses between the Domestic Pea (Pisum sativum subsp. sativum) and Tall Wild Pea (Pisum sativum subsp. elatius). Agronomy 2020, 10, 1869.

31. Rodiño, A.P.; Riveiro, M.; De Ron, A.M. Implications of the Symbiotic Nitrogen Fixation in Common Bean under Seasonal Water Stress. Agronomy 2021, 11, 70. [CrossRef]

32. Chen, T.; Katz, D.; Naim, Y.B.; Hammer, R.; Daniel, B.H.B.; Rubin, A.E.; Cohen, Y. Isolate-Dependent Inheritance of Resistance Against Pseudoperonospora cubensis in Cucumber. Agronomy 2020, 10, 1086. [CrossRef] 